\title{
A Study on Pricing Efficiency and Replication Strategy of Exchange Traded Funds
}

Kompalli Sasi Kumar*

Associate Professor-Finance, Siva Sivani Institute of Management, $\mathrm{NH}-7$, Kompally, Secunderabad - 500100, Telangana, India

\begin{abstract}
The study mainly investigating the pricing efficiency and replication strategy of exchange traded funds in the select segment of Equity ETFs and Gold ETFs during the period of 2012-2017. The study employed the famous market model (CAPM) to examine the replication strategy, pricing efficiency, tracking error and persistence performance of select exchange traded funds. The study concludes that Equity ETFs viz., Edelwiese AMC ETF, Motilal Oswal AMC ETF, Quantum AMC ETF and Gold ETFs viz., AIXS Gold ETF, IDBI Gold ETF, Quantum Gold ETF are adopting Selective replication strategy during the study period. During the study period it was evident that except Edelweiss AMC ETF, all other ETFs viz., Motilal Oswal AMC ETF, Quantum AMC ETF, Axis Gold ETF, IDBI Gold ETF, Quantum Gold ETFs are closely tracking the index and managing the tracking errors at an acceptable level. It indicates that all five funds are replicating the index closely. The study revelead that except Motilal Oswal M-50 ETF remaining all ETFs viz., Edelweises Equity ETF, IDBI Gold ETF, Quantum Equity ETF, Axis Gold ETF, Quantum NIFTY Gold ETFs are delievring premiums to investors.
\end{abstract}

Keywords: Replication Strategy, Passive Investment, Tracking Error, Persistence Performance

\section{Introduction}

Mutual Fund Industry currently managing a corpus of 17 lakh crore AUM, with CAGR of 38\% (2010-16) as per AMFI 2016 and PWC data. Major contribution to this growth in the industry from Systematic Investment Plan (SIP) accounts, every month 6 lakh SIP account are adding in the market in various funds. In the current financial year i.e. 2018-19 the industry expecting a growth of $14-15 \%$ in the mutual fund industry. To catch up this growth cycle and to launch innovative fund products, AMCs are promoting ETFs as an alternative to conventional investment avenues to retail investors. Exchange Traded Funds (ETFs) creation and redemption simply like a depository receipt and large dealers will issue these receipts in the form of investment schemes. ETFs tracks the indexes as well as list on a stock exchange and trading takes place daily. Fundamentally these are passive funds in the market with low expense ratio and in the low tax bracket with minimal brokerage charges tied with high liquidity . Transaction price of ETFs will be the quoted price in the market and a trading account is required for purchasing these funds. Just like a common stock these ETFs will trade in the stock exchanges associated with the characteristics of short sale and trading on margins.

Exchange Traded Funds (ETF) a passive investment in the mutual fund industry with AMCs was in the lime light recently (Jan 2018) with the circular issued

*Email: sasikumark@ssim.ac.in sasikumarkompalli@gmail.com 
by SEBI regarding benchmarking of mutual funds performance against Total Return Index (TRI), than against Price Return Index (PRI), a conventional way of benchmarking the performance of mutual funds. These ETFs are like depositories in mutual fund market.

Investment in any market related asset comprises of two components of return. One is capital gain generated by the asset, which is the difference between the initial price of the asset and ending market price of the asset at the time of sale. Second one is cash payments to investors in the form of dividends and interest paid. Price Return Index(PRI) captures only capital gain portion, while Total Return Index (TRI) captures both capital gain and cash payments.

Mutual Funds are actively managed funds, where as Exchange Traded Funds are Passively managed asset class, in this connection investors started comparing the various parameters of both the funds viz., Expense Ratio( Index Funds(1\%-1.5\%) VS Exchange Traded Funds(0.1\%), Brokerage Fee, Returns, Tracking Error, NAVs, Fund management style etc., There are numerous of reasons supporting the growth of such funds in the current market trends viz., Central Govt. Divestment in PSUs, Retirement funds through ETFs, Bharat 22 ETFs etc.,

ETF is a pooled investment vehicle, one can purchase shares directly from brokerage account, just like individuals buys a stock on exchange. Orders to buy and sell a mutual fund can be done only once in a day after the close of trading hours, whereas ETF trades can happen anytime in the open market conditions. Three major opportunities that ETF's possess which mutual funds doesn't are selling short, placing limit orders and buying on margin.

In simplest terms, ETF's tracks the indexes like NASDAQ, S\&P500, Dow Jones and so on. When a share of ETF is purchased, it is said that the portfolio of stocks is purchased which tracks the yield and returns from their native indexes. ETF's do not try to outperform the stock market or index, but they try to be the stock market and replicate the performance of the index.

\section{Replication Strategy of an ETF}

The goal of an ETF is to replicate its index as closely as possible. At the same time, the ETF investor receives all income and dividends generated from the underlying index. The classic method of replication is the physical replication or full replication. If, the ETF directly holds all the securities of the index, this is known as full replication. Synthetic or selective replication is that which allows ETF investors to invest in new asset classes. Synthetic ETF's are used to replicate only some indices more efficiently.

\section{Tracking Error of an ETF}

Tracking error measures the difference between the return of a fund and its underlying benchmark index. Tracking error is the measure of the volatility. Most of the time tracking error of an index fund is small. A small tracking error says that the passive fund is following its index closely where as a large tracking error means that the fund is moving above the index and trying to generate higher alphas to investors with higher risk. In simple terms it says, how closely the funds and index are during the period. It is an indicator of the quality of replication.

\section{Pricing Efficiency of ETF's}

Generally, ETF's are quoted by two prices: NAV and market price. NAV's are determined by the market values of the securities held and market prices are based on the supply and demand of the market participants. Therefore, there are very low chances of market prices and NAV's of ETF's to be identical. This enables cost and arbitrage opportunity for the investors.

Like stocks, ETF's also have a bid price- the highest price any investor is willing to pay for the ETF and ask price- the lowest price any seller is willing to accept. If the demand for the fund shares exceed supply it is said the price is at a premium to NAV and vice versa.

\section{Literature Review}

Purohit (2015) study on "Pricing Efficiency and Performance of Exchange Traded Funds in Indiał", 
found that Exchange Traded Funds (ETFs) are a remarkable example of financial innovation that provides the investors with unique feature of a combination of mutual fund and an ordinary corporate stock. The present study is motivated by the need to examine the performance, index tracking capabilities and pricing efficiency of ETFs. The purpose of the study is to address three objectives: (i) do the ETFs fully replicate the returns of the underlying benchmark; (ii) is there any pricing deviation between trading price and NAV of the respective ETFs studied; and (iii) the magnitude and persistence of premium/discounts in the market. The study concluded that substantial portion of tracking error was observed in the ETFs.

Swathy's (2015) study on ETFs are mutual fund schemes that are listed and traded like a stock on the exchange. An ETF is a hybrid financial product, bearing the twin features of a stock and a mutual fund. The ETF market is efficient and deserves credit from international investors seeking exposure to an emerging stock market.

Narend (2014) study on "Performance of ETFs and Index Funds", found that ETFs outperformed Index Funds. One of the noteworthy contribution is Alpha negative for both fund categories i.e. funds are unable generate excess returns to investors.

Chu's (2011) study on "Tracking errors and their determinants: evidence from Hong Kong Exchange traded funds" examined the size and factors affecting the tracking errors using the daily figures of the Exchange Traded Funds (ETFs) traded in Hong Kong stock market. The results revealed that the tracking errors are comparatively higher than US and Australian ETFs. The magnitude of the tracking errors is also found to be negatively related to the size, but positively related to the expense ratios of the funds, which are consistent with the previous studies.

Maluf's (2011) study on "Empirical Evidence: Arbitrage with Exchange-traded Funds (ETFs) on the Brazilian Market" investigated the efficiency of the valuation process of the iShares Ibovespa Fundo de an exchange traded fund in Brazil with respect to the fair value of the shares traded in Ibovespa Index. The results show that the fund shares are more volatile than their benchmark asset. In the long term, the series proved to be strongly co-integrated with the index.

Verdu's (2012) thesis on "The Efficiency of ExchangeTraded Funds as a market investment", investigated whether ETFs and LIETFs are efficient products substitute for market indices, or multiples of the market indices, around the globe and which factors are responsible for the mismatches in the tracking and pricing functions. The study showed that, in general, both ETFs and LIETFs, seem to be rather efficient in keeping their market prices close to their NAV.

Rompotis's G (2012) study on "The German Exchange Traded Funds", examined the performance and trading characteristics of 43 passively managed German ETFs trading on XTRA exchange during the period 2003-05. The study used daily trading prices, NAVs and Bid, Ask values of Index and ETFs to study the risk and return characteristics of ETFs by using simple regression and cross sectional regression analysis. The study developed six different cross-sectional regressional models to study the interaction among the main variables viz., return, risk, tracking error, expenses ratio and spread, turnover. The study concluded that return and risk are positively related, where as return is negatively related to tracking error. Volatility is positively correleated to tracking error, premium, Intraday volatility. The main finding is average ETF does not adopt a full replication.

Kostovetsky (2003) examined on Exchange-traded funds (ETFs) and Index Funds trading patterns and concluded that the key areas of difference between the two instruments are management fees, shareholder transaction fees, taxation efficiency, and other qualitative differences. Tracking error is difficult to model because there isn't a true benchmark for comparison.

\section{Objectives of the study}

To understand the replication strategy of select ETFs, i.e. whether ETF's adopt full replication or selective replication 
To investigate the pricing efficiency, tracking error and persistence of premium/discounts over one-day timelag of select ETFs.

\section{Methodology of the study}

The data required for the study has been collected from various websites of AMCs, NSE India and Yahoo India Finance etc., The study has been undertaken for a period of 5 years (2012-17). During this period stock market was very vibrant and experienced volatility, hence it was chosen for research. To examine the replication strategy and pricing efficiency of select Equity ETFs and Gold ETFs, the study used software's like MS-Excel for statistical analysis.

\section{Data Analysis Model}

\subsection{Replication Startegy}

To examine the quality of replication strategy in select Equity ETFs and Gold ETFs, the study employed CAPM Model.

$\mathrm{R}_{\mathrm{pt}}=\alpha_{\mathrm{p}}+\beta_{\mathrm{p}} \mathrm{R}_{\mathrm{bt}}+\varepsilon_{\mathrm{pt}}$

$\alpha_{\mathrm{p}}$-represents the constant returns an ETF manager can achieve

$\mathrm{R}_{\mathrm{pt}}$ - closing returns of the market price

$\mathrm{R}_{\mathrm{bt}}$ - benchmark returns

$\beta_{\mathrm{p}}$ - represents sensitivity of the funds

Alpha coefficient measures the extra returns generated by the fund mangers, independt of index returns. Beta coefficient measures the systematic risk of ETFs and reflects aggressiveness of fund managers in adopting replication strategies. Based on the regression results, it can be explored that if beta is close to 1 , it reflects full replication strategy, where in all funds will be invested in the underlying benchmark in the same weightage. If the beta value is less than 1, it reflects that the ETF is selectively replicated, which means fund managers deviated from passive investment strategy and invested in selected stocks for creation of efficient replication of index (Rompotis G, 2012).

Tracking error- the difference between the index returns and the benchmark portfolio.

$1^{\text {st }}$ method of tracking error- $\left|e_{p}\right|$ the absolute difference between ETF return and index return.

$2^{\text {nd }}$ method is the standard deviation of difference between the returns.

Pricing efficiency- closing prices and NAV's are taken as inputs for regression. If the regression coefficient beta lies above 1, it is said that ETF is trading at premium and if the coefficient is below 1, it is trading at discount.

To test the persistence of the premium and discounts, one-day time lag regression is used. To detect the arbitrage opportunities and market imperfections.

\section{Results and Discussion}

Table 1 presents the details of select list of Equity ETFs and Gold ETF schemes with the underlying asset during the study period.

Table 1. Select funds details

\begin{tabular}{|l|l|l|l|l|l|l|l|}
\hline Sno & Fund name & Name of the company & Date of inception & symbol & Index/ benchmark & Analysis period & Number of observations \\
\hline & Equity ETFs & & & & & & \\
\hline 1 & Edelweiss AMC & $\begin{array}{l}\text { Edelweisis exchange traded } \\
\text { scheme }\end{array}$ & $8^{\text {th }}$ May 2015 & Niftyees & Nifty 50 & $2015-2017$ & 261 \\
\hline 2 & Motilal Oswal AMC & Most shares m50 & $28^{\text {th } \text { july } 2010}$ & M50 & Nifty 50 & $2012-2015$ & 1342 \\
\hline 3 & Quantum AMC & Quantum index fund & $10^{\text {th } \text { july } 2008}$ & Qnifty & Nifty 50 & $2012-2015$ & 1017 \\
\hline & Gold ETF & & & & & & \\
\hline 4 & Axis gold ETF & Axis mutual fund & November 2010 & Axisgold & Gold futures & $2012-2015$ & 1317 \\
\hline 5 & IDBI gold ETF & IDBI AMC & November 2011 & Idbigold & Gold futures & $2012-2015$ & 1318 \\
\hline 6 & Quantum gold ETF & Quantum mutual fund & February 2008 & Qgoldhalf & Gold futures & $2012-2015$ & 1326 \\
\hline
\end{tabular}


From Table 1 it can be observed that the study selected three Equity ETF's and three Gold ETF's and whose level of replication can be known through analyzing the beta values. $\operatorname{Beta}(\beta)$ describes the sensitivity of fund returns to the index movements, thereby, measuring the systematic risks the ETF's could encounter

Table 2 presents replication analysis of closing returns and ETFs. From the results it is clearly evident that both Equity and Gold ETFs adopted selective replication strategies i.e fund managers selectively picking the stocks in the portfolio. It clearly indicates that during the market imperfections fund managers are opting for risky bets in the fund, resulting in additional risk to investors. The results of the study are in line with the previous research works viz., Rompotis G (2006) study on "An Emperical Look on Exchnage Traded Funds" and Harsh \& Nidhi (2015) study on "Pricing Efficiency and Performance of Exchange Traded Funds".

Table 3 presents the replication analysis of the closing returns of the Net Asset Values and ETF's for both Equity ETFs and Gold ETFs. It is observed that all ETFs adopting selective replication strategies. The reasons could be because of the effects of demand and supply of the NAV's.

Tracking error analysis: Tracking error measures the standard deviation of the difference in index return and the underlying bench mark index. In this research, two methods of tracking error have been used to know how closely the fund is moving with the underlying bench mark index. This method is an indication of the quality of replication.

Tracking error TE1: first, the absolute difference between the returns of the index fund and the underlying benchmark index are calculated.

$\left|e_{p}\right|$ the absolute difference between ETF return and index return.

$\mathrm{TE} 1={ }^{\mathrm{n}} \sum_{\mathrm{t}=1}\left|\mathrm{e}_{\mathrm{p}}\right| / \mathrm{n}$

Here $e_{p}=R_{p t}-R_{b t}$.

$\mathrm{R}_{\mathrm{pt}}$ is the closing returns of the portfolio and,

$\mathrm{R}_{\mathrm{bt}}$ is the closing returns of the underlying bench mark index.

The underlying index for Equity ETF's is Nifty50 and Gold ETF's is Gold futures.

Tracking error TE2: Standard Error of the ETF's are taken after performing the regression analysis between the closing returns of the Equity and Gold ETF's and the underlying bench mark index. The Study adopted

Table 2. Replication Analysis of Closing Returns and ETF's

\begin{tabular}{|l|l|l|l|l|l|l|}
\hline Serial number & ETF TYPE & Beta & Alpha & $\mathrm{R}^{2}$ & Confidence level & Type of strategy \\
\hline 1 & M-50 Motilal ETF & 0.745214 & 0.000230 & 0.566506 & $95 \%$ & Selective replication \\
\hline 2 & Q Nifty- Quantum ETF & 0.860613 & -0.000166 & 0.243511 & $95 \%$ & Selective replication \\
\hline 3 & Edelweisis Niftyees ETF & 0.533569 & 0.0000988 & 0.020361 & $95 \%$ & Selective replication \\
\hline 4 & Axis GOLD ETF & -0.005936 & $-3.56 E 05$ & 0.0005580 & $95 \%$ & Selective replication \\
\hline 5 & IDBI GOLD ETF & -0.005757 & $7.15 E 06$ & 0.0005322 & $95 \%$ & Selective replication \\
\hline 6 & Q Nifty GOLD ETF & -0.0001428 & $-6.36 E 06$ & 0.0000445 & $95 \%$ & Selective replication \\
\hline
\end{tabular}

Table 3 Replication analysis of the NAV's and ETF's

\begin{tabular}{|l|l|l|l|l|l|l|}
\hline Serial number & ETF TYPE & Beta & Alpha & $\mathrm{R}^{2}$ & Confidence level & Type of strategy \\
\hline 1 & M-50 motilal ETF & 0.168968 & 0.000420 & 0.000041 & $95 \%$ & Selective replication \\
\hline 2 & Qnifty- Quantum ETF & 0.999454 & 916 E06 & 0.931732 & $95 \%$ & Full replication \\
\hline 3 & Edelweisis Niftyees ETF & 0.372728 & 0.000875 & 0.002991 & $95 \%$ & Selective replication \\
\hline 4 & Axis GOLD ETF & -0.000966 & $-1.69 E 05$ & 0.000146 & $95 \%$ & Selective replication \\
\hline 5 & IDBI GOLD ETF & -0.003120 & $2.09 E 06$ & 0.0000003 & $95 \%$ & Selective replication \\
\hline 6 & Qnifty GOLD ETF & -0.000822 & $-5.42 E 06$ & 0.000107 & $95 \%$ & Selective replication \\
\hline
\end{tabular}


standard error as a measure to estimate the tracking error in the second method.

Table 4 depicts the results of tracking error in two methods. The study examined that the maximum tracking error average is for Edelweisis AMC equity ETF with the value 0.2392 , i.e this ETF is not following the index closely. While rest of the passive funds are closely following the ETF's with small tracking errors. Alpha generation is the key for selection of any fund in the industry, in case of higher tracking errors ETFs are adopting more risky strategies (viz., churning in the fund in terms of sector allocations and cash holding limits) for generating returns.

\section{Pricing Efficiency analysis of ETF's by calculating} premium and discounts: To examine the pricing efficiency of the ETFs, the study considered a linear relationship between closing trading prices and the Net Asset Values of the ETF's to run a regression, thereby, the beta value is used for interpreting the pricing efficiency of the ETFs. The closing prices and the NAV's on the daily basis are taken for both Equity and Gold ETF's for five years except for Edelweiss which is for three years, because of insufficient data.

A hypothesis has been drawn to know whether the ETFs is trading at a premium or discount.
Hypothesis 1-

$\mathrm{H}_{0}=$ Trading price of ETF is independent of its Net Asset Value

$\mathrm{H}_{\mathrm{A}}=$ Trading price of ETF is not independent of its Net Asset Value.

TP-ETF ${ }_{i}=\alpha_{i}+\beta_{i}$ NAV-ETF $_{i}$ Regression (1)

Where, TP-ETF ${ }_{\mathrm{i}}$ is the trading price of the ETF

NAV-ETF ${ }_{i}$ is the Net Asset Value if the ETF

$\mathrm{H} 0: \beta_{\mathrm{i}}=0$ and $\mathrm{HA}: \beta_{\mathrm{i}} \neq 0$.

If the regression coefficient beta lies below 1 it is to be noted that the ETF is trading at discount and if the regression coefficient beta is closer or equals to 1 it is to be noted that the ETF is trading at a premium.

Table 5 depicts the results of premiums /discounts generated by ETFs during the study period. From the table it is evident that except Motilal Oswal M-50 Equity ETF (beta value $=0.11$ ) remaining all ETFs delivered premiums to investors viz., Q Nifty Quatnum Equity ETF (Beta value=0.99), Axis Gold ETF (Beta Value=0.96), and Q Nifty Quantum Gold ETF (Beta

Table 4. Tracking Error analysis

\begin{tabular}{|l|l|l|l|l|}
\hline Serial no & Equity ETF & Tracking error TE1 & Tracking error TE2 & Average of TE1 and TE2 \\
\hline 1 & Edelweiss AMC & 0.019287 & 0.229972 & 0.249259 \\
\hline 2 & Motilal Oswal AMC & 0.007787 & 0.041438 & 0.049225 \\
\hline 3 & Quantum AMC & 0.005621336 & 0.020461 & 0.026082 \\
\hline & Gold ETF & & & \\
\hline 1 & Axis gold ETF & 0.01369 & 0.002184 & 0.015874 \\
\hline 2 & IDBl gold ETF & 0.017323 & 0.002191 & 0.019514 \\
\hline 3 & Quantum gold ETF & 0.012598 & 0.001860 & 0.014458 \\
\hline
\end{tabular}

Table 5. Premium And Discount Generated By ETFs

\begin{tabular}{|l|l|l|l|l|}
\hline Serial number & ETF TYPE & Beta & Alpha & Premium/ Discount \\
\hline 1 & M-50 Motilal Oswal ETF & 0.119413 & 73.46013 & Trading at discount \\
\hline 2 & Q Nifty- Quantum ETF & 0.995251 & 1.823941 & Trading at Premium/ Closer to Perfection \\
\hline 3 & Edelweisis Niftyees ETF & 0.768928 & 2196.536 & Trading at Premium/ Closer to Perfection \\
\hline 4 & Axis GOLD ETF & 0.967703 & 64.83521 & Trading at Premium / Closer to perfection \\
\hline 5 & IDBI GOLD ETF & 0.771240 & 597.3209 & Trading at Premium/ Closer to Perfection \\
\hline 6 & Qnifty GOLD ETF & 0.894596 & 138.2543 & Trading at Premium/ Closer to Perfection \\
\hline
\end{tabular}


Value $=0.89$ ), IDBI Gold ETF (Beta Value=0.77), Edelwess Niftyness ETF (Beta Value $=0.76$ ) with beta values close to 1 .

Persistence of Premiums and Discounts over oneday time lag: To test the persistence of the premium and discount of the ETF through one-day time lag, regression is used.

This analysis considers a hypothesis which is

\section{Hypothesis 1}

$\mathrm{H}_{0}=$ Premium/Discount of day $(\mathrm{t})$ is independent of the Premium/Discount of the day ( $\mathrm{t}-1)$.

$\mathrm{H}_{\mathrm{A}}=$ Premium/Discount of day $(\mathrm{t})$ is not independent of the Premium/Discount of the day ( $\mathrm{t}-1)$.

The equation is:

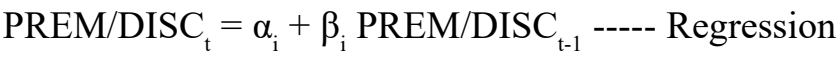
(2)

where PREM/DISC $\mathrm{t}_{\mathrm{t}}=$ Premium or Discount on Day $\mathrm{t}$

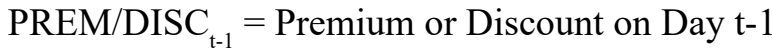

$\mathrm{H}_{0}: \beta_{\mathrm{i}}=0$ and $\mathrm{H}_{\mathrm{A}}: \beta_{\mathrm{i}} \neq 0$

If the regressed beta value of the ETF is nearer to zero implies that the arbitrage mechanism would vanish the premium and discount on the same day/trading day. Otherwise, if the beta value of the ETF is nearer to 1 implies that the premium and discounts remain for few days in the market. It creates arbitrage opportunities to investors.
Table 6 depicts the persistence of premium and discount on ETFs with one day time lag. It can be observed that Axis Gold ETF (Beta Value=0.95) and Q Nifty Quantaun Gold ETF (Beta Value=0.96) beta values are close to 1 and premium and discounts will stay in the market for few days and creates arbitrage opportunities to investors. In case of Q Nifty Quantum ETF (Beta Value $=0.26$ ) and IDBI Gold ETF (Beta Value $=0.463$ ), the premium/discount will not stay for long period and on the same trading day it will vanish.

\section{Findings of the Study}

Normally, there are two methods of studying the functioning of ETFs. First method, is Pricing Efficiency, which is the difference between the market price of the fund to NAV of the fund. Pricing Efficiency (premiums/discounts) persists for a short period of time i.e.intraday. Second method is Tracking Efficieny, which is the difference between the NAV of the fund to repliciation benchmark.

In the recent academic literature, tracking efficiency or trading efficiency gained much attention due to persistent trends in the stock markets as well as practioners and investors examining the skills of the fund managers in replicating the benchmark. The present paper examined both the efficiencies in the ETFs in the category of Equity and Gold.

The study revealed that across all category of funds viz., Motilal Oswal AMC ETF, Quantum AMC ETF, Axis Gold ETF, IDBI Gold ETF, Quantum Gold ETFs adopting selective replication strategies as well as depicting the tracking efficiency significantly. This is purely in line with the results of earlier studies on passive hedge funds replication strategies viz., Hartman

Table 6. Persistence of premium and discount one-day time lag

\begin{tabular}{|l|l|l|l|l|}
\hline Serial number & ETF TYPE & Alpha & Beta one day lagged & Persistence of ETF \\
\hline 1 & M-50 Motilal ETF & 5.656357 & 0.500931 & Market is imperfect and the Premiums/discounts stay for few days \\
\hline 2 & Qnifty- Quantum ETF & -1.459982 & 0.267022 & Premium/discount vanish on the same day due to arbitrage mechanism. \\
\hline 3 & Edelweisis Niftyees ETF & 75.52003 & 0.558776 & Market is imperfect and the Premiums/discounts stay for few days \\
\hline 4 & Axis GOLD ETF & -1.022207 & 0.954510 & Market is imperfect and the Premiums/discounts stay for few days. \\
\hline 5 & IDBI GOLD ETF & -21.80247 & 0.463362 & Premium/discount vanish on the same day due to arbitrage mechanism \\
\hline 6 & Qnifty GOLD ETF & -0.64306 & 0.966740 & Market is imperfect and the Premiums/discounts stay for few days. \\
\hline
\end{tabular}


F \& Huigen C (2017) study on "Factor-Based Hedged Fund Replication Using Exchange Traded Funds", used monthly data of nine ETFs and eleven differet hedged fund returns during 2008-16. The study revelead that Motilal Oswal M-50 ETF is trading at a discount and remaining all funds, during the market imperfections ETFs viz., Quantum Equity ETF, Axis Gold ETF, Q NIFTY Gold ETFs, Edelwise Equity ETF, IDBI Gold ETF are delievring premiums to investors. Majority of the funds are trading at preium. As funds are passive in nature, tracking error plays a crucial role in inculsion of the funds in the portfolio of investors. Fund Managers are directed to curtail the tracking error of these type of funds viz., ETFs and Index Funds, as far as possible, so that investors will diversify their investments into these funds for long term investment.

\section{Bibliography}

Amenc, N., \& Martellini, L., Meyfredi, J.-C., Ziemann, V. (2010). Passive Hedge Fund Replication-Beyond the Linear Case. European Financial Management. 16(2), 191210. https://doi.org/10.1111/j.1468-036X.2008.00448.x
Chu, P. K.-K. (2011). Study on Tracking Errors and their Determinants: Evidence from Hong Kong Exchange Traded Funds, Routledge Taylor and Francis Group, 7.

Hasanhodzic, J., \& Lo, A. W. (2007). Can Hedged Funds Returns be Replicated?: The Linear Case. Journal of Investment Management. 5(2), 5-45.

Kostovetsky, L. (2003). Index Mutual Funds and Exchange Traded Funds. Summer.

Maluf, Y. S. (2011). Empirical Evidence: Arbitrage with Exchange Traded Funds (ETFs) on the Brazilian Market. XIth Brazilian Finance Meeting, Rio de Janeiro, RJ., 11.

Narend, S. (2014). Performance of ETF and Index Funds. NSE Paper, 18.

Purohit, H. (2015). Pricing Efficiency and Performance of Exchange Traded Funds in India. IUP- National Ninth Conference on Indian Capital Market-Emerging Issues, 21. Rompotis, G. (2012). The German Exchange Traded Funds. The IUP Journal of Aplied Finance, 18(4).

Swathy. (2015). An Empirical Analysis of Pricing Efficiency of Exchange Traded Funds in India. International Journal of Engineering and Management Sciences, 5.

Verdu. (2012). The Efficiency of Exchange-Traded Funds as a market investment. Master Thesis, Tilburg University. 